\title{
USE OF PROSTATE AND BLADDER SONOMORPHOLOGY FOR DIAGNOSIS OF BLADDER OUTLET OBSTRUCTION IN PATIENTS WITH SYMPTOMATIC BENIGN PROSTATIC HYPERPLASIA
}

\author{
By
Ismail Fatouh Rady, Sabri Mahmoud Khaled, Abul-Fotouh Abd El- Maguid Abul-Fotouh, Mourad Mahmoud Mourad

Department of Urology, Al-Azhar Faculty of Medicine, Cairo, Egypt

Corresponding author: Ismail Fatouh Rady,

Mobile: 01004592683,E-mail: ismailrady@ yahoo.com

\begin{abstract}
Background: Benign prostatic hyperplasia (BPH) is a common urological problem more frequently seen in elderly people causing lower urinary tract symptoms (LUTS). About $28 \%$ of patients with BPH have moderate or severe LUTS and a considerable portion of these patients require LUTS treatment, pressure flow studies PFS is the gold standard for diagnosing obstruction, however the test is invasive, unpleasant costly, time consuming and technically difficult with limited availability to the patient.

Objective: To evaluate the accuracy of the bladder and prostate sonomorphologic parameters for the diagnosis of bladder outlet obstruction (BOO) in patients with lower urinary tract symptoms (LUTS) with benign prostatic hyperplasia (BPH).

Patients and Methods: A prospective clinical trial was carried out during the period from January 2017 to January 2019 at the Urology Departments; Al-Hussein and Sayed Galal, Al-Azhar University Hospitals, and Police Authority Hospital, Cairo, Egypt to 512 patients seeking treatment for LUTS/BPH underwent a series of measurements, including medical history with LUTS assessment using the International Prostate Symptom Score (IPSS), physical examination with digitorectal and focal neurological examinations, routine urinalysis, and serum creatinine and prostate-specific antigen (PSA) measurements.

Results: During the study period, 209 patients completed the follow up protocol and included in the study, the mean age of the study population was 64.51 years, the mean total IPSS score was 19.18 , the mean duration of symptoms was 6.4 mo., the mean total prostate volume, transitional zone volume, and transitional zone index were $42.5 \mathrm{~g}, 25.7 \mathrm{~g}$, and 0.6 respectively. The mean bladder parameters studied intravesical prostatic protrusion, bladder wall thickness was $11.3 \mathrm{~mm}, 4.85 \mathrm{~mm}, 30.1 \mathrm{~g}$ respectively, the mean prostate parameters studied prostate urethral length, prostate urethral angel were $41.8 \mathrm{~mm}$ and $34.3^{\circ}$. Out of 209 patients studied $113(54.1 \%)$ patients were obstructed (BOO group) and 96 (45.9\%) were not (non- BOO group). All parameters were comparable between the two groups.
\end{abstract}

Conclusions: Some sonomorphologic parameters of bladder and prostate (IPP, PUA, BWT and Qmax) are useful alternative to PFS for diagnosis of symptomatic BOO/BPH.

Keywords: Bladder outlet obstruction, Lower Urinary Tract Symptoms, Benign Prostatic Hyperplasia. 


\section{INTRODUCTION}

Bladder outlet obstruction (BOO) is the main sequel of benign prostatic hyperplasia $(\mathrm{BPH})$, and it results from a variety of functional and anatomical factors such as mechanical compression of the prostatic urethra by enlarged prostate, bladder neck elevation, increased prostate urethral angle, and increased smooth muscle tone in the prostatic urethra. The diagnosis of $\mathrm{BOO} / \mathrm{BPH}$ is a challenging issue that has been debated for decades (Mangera et al., 2014).

Several methods have been used for the diagnosis of $\mathrm{BOO} / \mathrm{BPH}$, such as symptom assessment using validated questionnaires, physical examination, and estimation of postvoid residual (PVR) urine volume and urinary flow rate. However, most of these tests are not exclusive to $\mathrm{BOO}$ (Berges and Oelke, 2011).

The pressure flow study (PFS) is considered the most useful test available for diagnosing BOO. However, this method is not accepted by many patients or clinicians as they consider it an invasive procedure associated with considerable patient's discomfort and unavoidable consequences such as introducing infection (Gammie et al., 2016).

Almeida et al. (2011) and Güzel et al. (2015) have evaluated the accuracy of bladder and prostate sonomorphologic parameters for the diagnosis of BOO/BPH. In spite of this, the clinical usefulness of these parameters and their potential use as markers for diagnosing BOO remain controversial. The biggest handicap is the absence of standardized values for these parameters. Additionally, the use of different methods for ultrasonography (USG), different transducer frequencies, different levels of bladder fullness during examinations, as well as the nonuse of PFS as a standard reference in most of studies, make previous results difficult to interpret and limit their use in clinical practice.

The aim of the present work was to evaluate the accuracy of the bladder and prostate sonomorphologic parameters for the diagnosis of bladder outlet obstruction (BOO) in patients with lower urinary tract symptoms (LUTS) with benign prostatic hyperplasia (BPH).

\section{PATIENTS AND METHODS}

This prospective clinical trial was carried out during the period from January 2017 to January 2019 at the Urology Department; Al-Hussein and Sayed Galal Hospital, Al-Azhar University; Cairo; Egypt. The research ethics committee of our institution approved the study protocol and all participants provided informed written consents before inclusion.

Out of 512 men seeking treatment for LUTS/BPH during the study period, 209 had the selective criteria and completed the required investigations.

All patients with LUTS/BPH underwent a series of measurements, including medical history with LUTS assessment using the International Prostate Symptom Score (IPSS), physical examination with digit rectal and focal neurological examinations, routine urinalysis, and serum creatinine and prostate-specific antigen (PSA) measurements. Patients who met the inclusion criteria were recommended for pelvic USG, transrectal USG and PFS. 


\section{Exclusion criteria:}

Abdominopelvic ultrasound scanning was done with the patients in supine position using a convex 3.5 to $6.5 \mathrm{MHz}$ probe of BK Medical, Flex Focus Ultrasound System (Herlev, Denmark). A real-time scanning was performed with an average bladder volume of $200 \mathrm{ml}$, BWT was assessed by measuring the thickness of the hypoechoic muscle between two hyperechoic layers corresponding to the serosa and mucosa $(\mathrm{mm})$. A minimum of 3 measurements were obtained from the anterior or lateral bladder walls and averaged (De Nunzio et al. 2020), UEBW was calculated using the method described by Ahmed and Bedewi (2016).

The total bladder volume was calculated from the outer dimensions using the formula for an elliptic volume, for which the outer dimensions were the sums of the mean DWT $\times 2$ to the maximal inner dimension in each of 3 directions (transverse, superior-inferior and anteriorposterior). Next, the bladder wall volume was obtained by subtracting the intravesical volume from the total bladder volume. The intravesical volume was calculated from the maximal inner dimensions using the formula for an elliptic volume. Finally, UEBW was calculated by multiplying the volume of the bladder wall by the specific gravity of 1. IPP: It was assessed by measuring the distance from the intravesical edge of the prostate to the base of the bladder in the mid-sagittal view (Lee et al., 2016).

Transrectal ultrasonography was performed for all participants. With the patients in left lateral position using the same ultrasound machine and $7.5 \mathrm{MHz}$ transrectal probe, the scanning was done.
Prostate volume was automatically calculated by integrated volumetric program, after measurement of transverse, superior-inferior and anterior-posterior diameters, using the formula: volume equal to $0.5236 \times($ width $) \times$ (length) $\times$ (height). The PUL was measured by the continuous tracing of the route of the urethra, which runs within the apex to the base of the prostate via the midsagittal image of ultrasonography. Prostatic urethral angel (PUA) was defined as the angle formed by 2 rays of both the proximal and distal prostatic urethra. The PUL and PUA were measured from the midsagittal image, which was taken when the pressure from the rectal probe was minimized, as suggested by (Kim et al., 2016).

Free uroflowmetry was done in all patients at the beginning of the test and before catheter fixation to avoid the false positive infra vesical obstruction caused by the mechanical obstructing effect of urethral catheter. Uroflowmetry was done using MMS, andromeda and laborie uroflowmetry machine. The test was performed for patients who could void per-urethra. A bell-shaped curve with Qmax more than $15 \mathrm{~mL} / \mathrm{sec}$. were considered normal. It was done while the patient was micturating freely in the standing position.

PFS was performed using a Multichannel Urodynamics System (Triton, Laborie, Toronto, Canada). Conventional filling cytometry was performed with the patients in the supine or sitting position by using a double lumen (6 French) catheter which was inserted transurethrally for filling and recording vesical pressure (Pves). 
Simultaneous Pabd monitoring was obtained through a fluid-filled rectal balloon catheter (10 French). The bladder was filled at a constant rate of $20 \mathrm{~mL}$ per minute by using $0.9 \%$ normal saline solution at room temperature.

Pressures were measured by using external pressure transducers that were zeroed to atmospheric pressure by using the level of the symphysis pubis as the reference height. To monitor measurement validity of the test, coughing was asked at regular intervals, immediately before the examination, during the whole storage phase and immediately after the examination. Coughing should consistently give similar pressure changes in Pves and Pabd. The difference between Pves and Pabd is called the Pdet which was calculated by the system at Qmax.

The patient urinated privately into a special toilet that has a container for collecting the urine and a scale. The equipment created a graph that showed changes in flow rate and pressure changes from second to second (Pdet at Qmax), during the voiding phase, subjects voided with good flow (Qmax >10 mL/second with a voided volume of $>150 \mathrm{~mL}$ ) and their detrusor pressure at Qmax 40 to 60 $\mathrm{cmH} 2 \mathrm{O}$ were considered as normal subjects.

According to pressure flow studies, patients were divided into two groups: obstructed and non-obstructed. The urodynamic results were correlated to the sonomorphologic parameters to predict the BOO.

\section{Statistical analysis:}

Results of the present study were statistically analyzed using SPSS 25 (IBM, USA). Data were represented as mean \pm standard deviation (SD), median (interquartile range) or number and percentage. Numerical data were compared using Mann- Whitney U test while categorical data were compared using Fisher exact test or Chi-square test, as appropriate. The level of significance at $P$ value $<0.05$ significant.

\section{RESULTS}

According to the presence or absence of $\mathrm{BOO}$ as confirmed by PFS, 113 $(54.1 \%)$ patients had BOO (BOO group) and $96(45.9 \%)$ were not (non- BOO group). The age of patients ranged from 50.00 to 86.00 years (median: 65.00 years; IQR: 15.00). All of patients presented mainly with LUTS. The median total IPSS was 20.00 (IQR: 1.50) and median duration symptoms was 6.00 months (IQR: 4.00). The PSA level was $\leq 4.00$ $\mathrm{ng} / \mathrm{mL}$ in all patients (median: 3.00 ng/mL; IQR: 0.70). Patients with BOO had significantly higher age $(p=0.025)$, total IPSS $(\mathrm{p}=0.002)$, voiding sub score $(\mathrm{p}=0.012)$, storage sub scores $(\mathrm{p}=0.001)$, QoL scores $(\mathrm{p}=0.009)$. No significant differences were observed between patients with and those without BOO, regarding the duration of symptoms and PSA level $\quad((\mathrm{p}=0.057$ and 0.974, respectively) (Table 1). 
Table (1): Demographic, clinical and laboratory data of studied patients, overall and in both groups

\begin{tabular}{|c|c|c|c|c|}
\hline $\begin{array}{ll}\text { Variables } & \text { Patients } \\
\end{array}$ & $\begin{array}{l}\text { Overall } \\
(\mathbf{n}=209)\end{array}$ & $\begin{array}{c}\text { BOO } \\
(n=113)\end{array}$ & $\begin{array}{c}\text { Non- BOO } \\
(n=96)\end{array}$ & $\begin{array}{c}\text { p- } \\
\text { value }\end{array}$ \\
\hline Age, years & & & & \multirow{5}{*}{0.025} \\
\hline Mean \pm SD & $64.51 \pm 9.69$ & $66.17 \pm 10.01$ & $62.56 \pm 8.97$ & \\
\hline Median & 65.00 & 66.00 & 62.50 & \\
\hline Min., max. & $50.00,86.00$ & $50.00,86.00$ & $50.00,83.00$ & \\
\hline IQR & 15.00 & 13.00 & 14.75 & \\
\hline IPSS, total & & & & \multirow{5}{*}{0.002} \\
\hline Mean \pm SD & 19.18 & $20.31 \pm 2.10$ & $17.85 \pm 4.95$ & \\
\hline Median & 20.00 & 20.00 & 19.00 & \\
\hline Min.,max. & $5.00,25.00$ & $17.00,25,00$ & $5.00,25.00$ & \\
\hline IQR & 1.50 & 3.00 & 2.00 & \\
\hline IPSS, voiding subscore & & & & \multirow{5}{*}{0.012} \\
\hline Mean \pm SD & $11.31 \pm 2.60$ & $11.96 \pm 1.73$ & $10.54 \pm 3.18$ & \\
\hline Median & 12.00 & 12.00 & 12.00 & \\
\hline Min., max. & $2.00,16.00$ & $2.00,16.00$ & $2.00,16.00$ & \\
\hline IQR & 1.00 & 1.00 & 2.00 & \\
\hline IPSS, storage subscore & & & & \multirow{4}{*}{0.001} \\
\hline Mean \pm SD & $7.77 \pm 1.78$ & $8.26 \pm 1.19$ & $7.19 \pm 2.13$ & \\
\hline Median & 8.00 & 8.00 & 8.00 & \\
\hline Min., max. & $3.00,11.00$ & $6.00,11.00$ & $3.00,11.00$ & \\
\hline IQR & 2.00 & 2.00 & 2.00 & \multirow{6}{*}{0.009} \\
\hline QoL score & & & & \\
\hline Mean \pm SD & $3.61 \pm 1.04$ & $3.82 \pm 0.86$ & $3.36 \pm 1.18$ & \\
\hline Median & 4.00 & 4.00 & 3.50 & \\
\hline Min., max. & $1.00,5.00$ & $2.00,5.00$ & $1.00,5.00$ & \\
\hline IQR & 1.00 & 2.00 & 1.00 & \\
\hline Duration of symptoms & & & & \multirow{4}{*}{0.057} \\
\hline Mean \pm SD & $6.45 \pm 3.71$ & $6.96 \pm 4.12$ & $5.86 \pm 3.07$ & \\
\hline Median & 6.00 & 6.00 & 5.00 & \\
\hline Min., max. & $1.00,30.00$ & $1.00,30.00$ & $1.00,15.00$ & \\
\hline IQR & 4.00 & 5.00 & 4.00 & \multirow{6}{*}{0.974} \\
\hline PSA, ng/dL & & & & \\
\hline Mean \pm SD & $3.16 \pm 0.67$ & $3.12 \pm 0.78$ & $3.21 \pm 0.51$ & \\
\hline Median & 3.00 & 3.00 & 3.00 & \\
\hline Min., max. & $0.70,4.00$ & $0.70,4.00$ & $1.22,4.00$ & \\
\hline IQR & 0.70 & 0.80 & 0.65 & \\
\hline
\end{tabular}

BOO, Bladder outlet obstruction; IPSS, International prostatic symptoms score; IQR, Interquartile range; PSA, prostatic specific antigen; SD, Standard deviation.

In overall patients, the median TPV was $40.00 \mathrm{cc}$ (IQR: 15.00) and median TZV was 24.00 cc (IQR: 9.00). The median PUL was $40.50 \mathrm{~mm}$ (IQR: 6.61), median IPP $10.88 \mathrm{~mm}$ (IQR: 2.48) and median PUA was 34.00o (IQR: 6.00).
Patients with BOO had significantly longer IPP and higher PUA $(p<0.001)$. No significant differences were observed between patients with and those without $\mathrm{BOO}$, regarding $\mathrm{TPV}, \mathrm{TZV}, \mathrm{TZI}$, and PUL (Table 2). 
Table (2): Prostate sonographic parameters in studied patients, overall and in both groups

\begin{tabular}{|c|c|c|c|c|}
\hline $\begin{array}{l}\text { Patients } \\
\text { Variables }\end{array}$ & $\begin{array}{l}\text { Overall } \\
(n=209)\end{array}$ & $\begin{array}{c}\text { BOO } \\
(n=113)\end{array}$ & $\begin{array}{c}\text { Non- BOO } \\
(n=96)\end{array}$ & $\begin{array}{c}\text { p- } \\
\text { value }\end{array}$ \\
\hline TPV, cc & & & & \multirow{5}{*}{0.079} \\
\hline Mean \pm SD & $42.54 \pm 14.30$ & $43.32 \pm 13.34$ & $41.62 \pm 15.37$ & \\
\hline Median & 40.00 & 40.00 & 37.50 & \\
\hline Min., max. & $27.00,110.00$ & $27.00,110.00$ & $28.00,105.00$ & \\
\hline IQR & 15.00 & 11.00 & 15.00 & \\
\hline TZV, cc & & & & \multirow{5}{*}{0.373} \\
\hline Mean \pm SD & 25.75 & $25.53 \pm 8.27$ & $26.01 \pm 10.66$ & \\
\hline Median & 24.00 & 26.00 & 23.00 & \\
\hline Min., max. & $15.00,70.00$ & $15.00,70.00$ & $15.00,70.00$ & \\
\hline IQR & 9.00 & 7.00 & 11.00 & \\
\hline TZI & & & & \multirow{4}{*}{0.369} \\
\hline Mean \pm SD & $0.63 \pm 0.07$ & $0.62 \pm 0.08$ & $0.64 \pm 0.07$ & \\
\hline Median & 0.65 & 0.65 & 0.63 & \\
\hline Min., max. & $0.38,0.73$ & $0.38,0.73$ & $0.49,0.73$ & \\
\hline IQR & 0.09 & 0.09 & 0.13 & \multirow{6}{*}{0.744} \\
\hline PUL, mm & & & & \\
\hline Mean \pm SD & $41.81 \pm 4.17$ & $41.64 \pm 3.74$ & $42.01 \pm 4.65$ & \\
\hline Median & 40.50 & 41.20 & 39.90 & \\
\hline Min., max. & $29.50,52.70$ & $29.50,48.80$ & $36.90,52.70$ & \\
\hline IQR & 6.61 & 4.18 & 7.30 & \\
\hline IPP, $\mathbf{m m}$ & & & & \multirow{4}{*}{$<0.001$} \\
\hline Mean \pm SD & $11.32 \pm 3.41$ & $13.27 \pm 3.10$ & $9.02 \pm 2.06$ & \\
\hline Median & 10.88 & 11.90 & 9.52 & \\
\hline Min., max. & $4.00,20.00$ & $6.80,20.00$ & $4.00,14.84$ & \\
\hline IQR & 2.48 & 3.90 & 3.98 & \multirow{6}{*}{$<0.001$} \\
\hline PUA & & & & \\
\hline Mean \pm SD & $34.36 \pm 3.98$ & $36.86 \pm 2.59$ & $31.42 \pm 3.26$ & \\
\hline Median & 34.00 & 37.00 & 32.00 & \\
\hline Min., max. & $24.00,42.00$ & $32.00,42.00$ & $24.00,38.00$ & \\
\hline IQR & 6.00 & 3.00 & 5.00 & \\
\hline
\end{tabular}

BOO, Bladder outlet obstruction; IPP, Intravesical prostatic protrusion; IQR, Interquartile range; PUA, Prostatic urethral angle; SD, Standard deviation; TPV, Total prostate volume; TZI, Transitional zone index; $\mathrm{TZV}$, transitional zone volume.

In overall patients, the median BWT $3.90 \mathrm{~mm}$ (IQR: 4.00), median UEBW 30.00 (IQR: 9.00). The PVR urine ranged from 0.00 to $150.00 \mathrm{cc}$ (median: 50.00; IQR: 68.00). Only 13 patients had PVR urine volume $>100.00 \mathrm{cc}$. Patients with BOO had significantly higher BWT, UEBW and PVR urine volume $(\mathrm{p}<0.001)$ (Table 3). 
Table (3): Urinary bladder sonographic parameters in studied patients, overall and in both groups

\begin{tabular}{|l|c|c|c|c|}
\hline Variables & $\begin{array}{c}\text { Overall } \\
(\mathbf{n = 2 0 9})\end{array}$ & $\begin{array}{c}\text { BOO } \\
(\mathbf{n = 1 1 3})\end{array}$ & $\begin{array}{c}\text { Non- BOO } \\
(\mathbf{n = 9 6})\end{array}$ & $\begin{array}{c}\text { p- } \\
\text { value }\end{array}$ \\
\hline BWT, mm & & & & \\
Mean \pm SD & $4.85 \pm 3.32$ & $6.77 \pm 3.40$ & $2.60 \pm 0.98$ & $<0.001$ \\
Median & 3.90 & 7.00 & 3.00 & \\
Min., max. & $1.30,22.00$ & $3.00,22.00$ & $1.30,4.20$ & \\
IQR & 4.00 & 4.00 & 1.95 & \\
UEBW & & & & \\
Mean \pm SD & $30.11 \pm 7.50$ & $33.88 \pm 6.95$ & $25.69 \pm 5.43$ & $<0.001$ \\
Median & 30.00 & 33.00 & 24.00 & \\
Min., max. & $15.00,46.00$ & $15.00,46.00$ & $15.00,33.00$ & \\
IQR & 9.00 & 8.00 & 6.00 & \\
PVR urine, cc & & & & \\
Mean $\pm S D$ & $50.26 \pm 40.76$ & $65.73 \pm 43.46$ & $32.04 \pm 28.09$ & $<0.001$ \\
Median & 50.00 & 60.00 & 50.00 & \\
Min., max. & $0.00,150.00$ & $0.00,150.00$ & $0.00,94.00$ & \\
IQR & 68.00 & 76.00 & 50.00 & \\
\hline
\end{tabular}

BOO, Bladder outlet obstruction; IQR, Interquartile range; SD, Standard deviation; TRUS, Transrectal ultrasonography; TPV, Total prostate volume; TZI, Transitional zone index; TZV, transitional zone volume.

Free uroflowmetry was performed for all patients. In overall patients, the Qmax ranged from 6.70 to $16.98 \mathrm{~mL} / \mathrm{sec}$. (median: 11.78; IQR: 5.20). The Qmax was significantly lower in patients with
BOO $(\mathrm{p}<0.001)$. In BOO group, 106 (93.8\%) had Qmax <15 mL/sec., compared with $7(6.2 \%)$ in non- BOO group $(\mathrm{p}<0.001)$ (Table 4).

Table 4: The Qmax in studied patients, overall and in both groups

\begin{tabular}{|c|c|c|c|c|}
\hline $\begin{array}{ll}\text { Pariables } & \text { Patients } \\
\end{array}$ & $\begin{array}{l}\text { Overall } \\
(n=209)\end{array}$ & $\begin{array}{c}\text { BOO } \\
(n=113)\end{array}$ & $\begin{array}{c}\text { Non- BOO } \\
(n=96)\end{array}$ & $\begin{array}{c}\text { p- } \\
\text { value }\end{array}$ \\
\hline Qmax, mL/sec. & & & & \\
\hline Mean \pm SD & $11.97 \pm 2.92$ & $10.56 \pm 2.20$ & $13.64 \pm 2.79$ & $<0.001$ \\
\hline Median & 11.78 & 10.78 & 14.98 & \\
\hline Min., max. & $6.70,16.98$ & $6.78,16.50$ & $6.70,16.98$ & \\
\hline IQR & 5.20 & 3.00 & 4.95 & \\
\hline Qmax Categories, $n(\%)$ & & & & \\
\hline$\geq 15 \mathrm{~mL} / \mathrm{sec}$ & $42(20.1)$ & $7(6.2)$ & $35(36.5)$ & $<0.001$ \\
\hline$<15 \mathrm{~mL} / \mathrm{sec}$. & 167 (79.9) & $106(93.8)$ & $61(63.5)$ & \\
\hline
\end{tabular}

BOO, Bladder outlet obstruction; IQR, Interquartile range; SD, Standard deviation; Qmax, Maximum flow rate.

\section{DISCUSSION}

In this study the patient symptoms (IPSS) was significantly correlated with patients' age, overall and in patients with BOO, with QoL, overall and in patients with and those without $\mathrm{BOO}$ and serum PSA level only in patients with BOO.

Statistically significant and good correlation was found between IPSS and QOL score, which was also supported by (Taneja et al., 2017). 
The relationships between prostate volume and IPSS have been described by Gnyawali and Sharma (2014) with no correlation detected. This data was further supported by our study, where no correlation was found in-between prostatic volume, and total and each component of IPSS.

There was no significant correlation between total IPSS score and prostate volume, transitional zone volume and transitional zone index. Thus, correlation between the prostate volume and IPSS is nil, and the size of the prostate is not be an important consideration to determine the need for therapy. However, the choice of therapy depends on the size of prostate. Therefore, we should not treat the volume of prostate; it's the symptoms and poor uroflowmetric variables that should be treated off (Luo et al., 2013).

In this study there was no correlation between LUTS and BOO. This was supported by many studies and that symptoms alone should not be used as the major indication for invasive therapy (Patel and Parsons, 2014). Also Xu et al. (2014) found that symptoms cannot differentiate between patients with and without urodynamic bladder outlet obstruction.

In this study IPP is a better predictor of obstruction with a cutoff value more than $10.88 \mathrm{~mm}$, with sensitivity and specificity $83.2 \%$ and $90.6 \%$, respectively. Comparable results had also been reported by Ahmed \& Bedewi (2016) and Kuo et al. (2016).

The prostatic urethra runs through the prostate from the base to the apex, making an anterior angle of $35^{\circ}$ at the proximal part of the verumontanum. This bend divides the urethra into proximal and distal regions (Kim et al., 2016).

The angle tends to be $>35^{\circ}$ in men with nodular hyperplasia but can also increase in men without nodular hyperplasia. An increased PUA, such as is found on cystoscopy examination, results in a higher bladder neck in men without lateral or median lobe enlargement. Although many urologists believe that a higher bladder neck might be a causal factor of bladder outlet obstruction and LUTS, the underlying reason remains poorly understood.

Positive significant correlation was observed in this study, as PUA increases, the $\mathrm{BOO}$ index increases, Patients with PUA $\geq 34^{\circ}$ were more likely to have outlet obstruction than were those with PUA $<$ $34^{\circ}$.

Ku et al. (2010) studied 260 men older than 50 years with IPSS more than 8 and Qmax less than 10 retrospectively. They recorded IPSS, voiding diary, prostatespecific antigen (PSA), PVR, pressureflow study and uroflowmetry, PUA, and IPP. Patients with higher PUA (PUA $\geq 35^{\circ}$ ) had higher PSA, larger prostate volume, higher maximal urethral closure pressure, higher detrusor pressure at maximum flow rate, and higher $\mathrm{BOO}$ index. But there was no relationship between the degree of IPP and PUA in that study.

A study, by Park et al. (2012) demonstrated that the PUA correlated with BOOI during pressure flow studies, but no significant correlation with urinary symptoms and Qmax.

In this study, the UEBW was higher in 113 obstructed men (BOO index greater 
than 40, mean UEBW $33.88 \mathrm{~g}$ ) than in 96 unobstructed men (mean UEBW $25.69 \mathrm{~g}$ ). However this difference was not significantly different. Ahmed and Bedewi (2016) found a significantly higher UEBW in the BOO group, with a high diagnostic accuracy at a cutoff value of $31.5 \mathrm{~g}$.

Bright et al. (2010) investigate the usefulness of UEBW as a predictor of the need for surgery for benign prostatic hyperplasia (BPH). The surgery rate was associated with a high UEBW ( $\geq 35 \mathrm{~g})$. In contrast Almeida et al. (2011) indicated that UEBW was not significantly correlated with BOO.

PVR was studied as a non-invasive parameter to predict bladder outlet obstruction, in our study there was a significant difference between those with and those without obstruction, the mean PVR volume of BOO group for non-BOO group, was not correlated well with obstruction, this may be because the increased PVR may be attributed to many bladder pathologies. Kalil and D'Ancona (2020), concluded that Isolated symptoms, classified by IPSS and PVR, could not differentiate patients with DU from those with BOO, but it was possible using urodynamic data. However, interpretation of significant PVR in favor of isolated benign prostatic obstruction (BPO) has been proposed in numerous studies (Chen et al., 2019). In this study the Qmax was one of the best predictors of obstruction with cutoff value of $15 \mathrm{ml} / \mathrm{sec}$. Trumbeckas et al. (2011) concluded that when combining Qmax cutoff value of 10 $\mathrm{ml} / \mathrm{s}$, prostate volume more than $40 \mathrm{~g}$ and IPSS score greater than 20 could predict bladder outlet obstruction.

\section{CONCLUSION}

USG measurements of BWT, PUA, IPP and Qmax were useful alternatives to PFS for the diagnosis of symptomatic BOO/BPH. Estimation of the optimal cutoff values of these parameters by routine suprapubic and transrectal USG was helped to solve the standardization issues and support their clinical usefulness. Moreover, the easy measurement of BWT, and IPP by suprapubic USG, and flow rate makes these parameters acceptable to both patients and physicians, and can be used for routine clinical evaluation of patients with symptomatic BPH.

Noninvasive sonomorphologic parameters of the bladder and prostate can be used with uroflowmetry for the detection of BOO in BPE patients; however, large study population is needed to standardize the cutoff value for diagnosis of BOO.

Conflict of interest: None.

\section{REFERENCES}

1. Ahmed AF and Bedewi M. (2016): Can bladder and prostate sonomorphology be used for detecting bladder outlet obstruction in patients with symptomatic benign prostatic hyperplasia? Urology, 98:126-31.

2. Almeida FG, Freitas DG and Bruschini H. (2011): Is the ultrasound- estimated bladder weight a reliable method for evaluating bladder outlet obstruction?. BJU international, 108(6):864-7. 
3. Berges $R$ and Oelke $M$. (2011): Age-stratified normal values for prostate volume, PSA, maximum urinary flow rate, IPSS, and other LUTS/BPH indicators in the German male community-dwelling population aged 50 years or older. World journal of urology, 29(2):171-8.

4. Bright E, Oelke M, Tubaro A and Abrams P. (2010): Ultrasound Estimated Bladder Weight and Measurement of Bladder Wall Thickness-Useful Noninvasive Methods for Assessing the Lower Urinary Tract?" The Journal of Urology, 184 (5): 1847-54.

5. Chen SF, Lee CL and Kuo HC. (2019): Change of Detrusor Contractility in Patients with and without Bladder Outlet Obstruction at Ten or More Years of follow-up. Scientific Reports, 9(1):1-6.

6. De Nunzio C, Lombardo $R$, Cicione A, Trucchi A, Carter S, Tema G, Nacchia A, Vicentini C, Tubaro A. (2020): The role of bladder wall thickness in the evaluation of detrusor under activity: Development of a clinical nomogram. Neurourology and Urodynamics, 39(4):1115-23.

7. Gammie A, Kaper M, Dorrepaal C, Kos T and Abrams P. (2016): Signs and symptoms of detrusor under activity: an analysis of clinical presentation and urodynamic tests from a large group of patients undergoing pressure flow studies. European urology, 69(2):361-9.

8. Gnyawali D and Sharma U. (2014): Correlation of Prostate Volume with International Prostate Symptom Score and Benign Prostatic HyperplasiaImpact Index in Benign Prostatic Hyperplasia. Journal of Society of Surgeons of Nepal, 17 (1): 6-10.

9. Güzel Ö, Aslan Y, Balcı M, Tuncel A, Keten T, Erkan A and Atan A. (2015): Can bladder wall thickness measurement be used for detecting bladder outlet obstruction?. Urology, 86(3):439-44.

10. Kalil J and D'Ancona CA. (2020): Detrusor under activity versus bladder outlet obstruction clinical and urodynamic factors. International braz j urol, 46(3):419-24.

11. Kim BH, Kim KH, Ko YH, Song PH, Kim TH and Kim BS. (2016): The prostatic urethral angle can predict the response to alpha adrenoceptor antagonist monotherapy for treating nocturia in men with lower urinary tract symptom: A multicenter study. Prostate international., 4 (1):30-5.

12. Ku JH, Ko DW, Cho JY and Oh SJ. (2010): Correlation between prostatic urethral angle and bladder outlet obstruction index in patients with lower urinary tract symptoms. Urology, 75(6):1467-71.

13. Kuo TL, Teo JS and Foo KT. (2016): The role of intravesical prostatic protrusion (IPP) in the evaluation and treatment of bladder outlet obstruction (BOO). Neurourology and Urodynamics, 35(4):535-7.

14. Lee A, Lee HJ, Lim KB, Huang HH, Ho H and Foo KT. (2016): Can intravesical prostatic protrusion predict bladder outlet obstruction 
even in men with good flow?. Asian journal of urology, 3(1):39-43.

15. Luo GC, Foo KT, Kuo T and Tan G. (2013): Diagnosis of prostate adenoma and the relationship between the site of prostate adenoma and bladder outlet obstruction. Singap Med J., 54(9):482-6.

16. Mangera A, Osman NI and Chapple CR. (2014): Assessment of $\mathrm{BPH} / \mathrm{BOO}$. Indian journal of urology: IJU: journal of the Urological Society of India, 30(2):177.

17. Park YJ, Bae KH, Jin BS, Jung HJ and Park JS. (2012): Is increased prostatic urethral angle related to lower urinary tract symptoms in males with benign prostatic hyperplasia/lower urinary tract symptoms?. Korean journal of urology, 53(6):410-3.

18. Patel ND and Parsons JK. (2014): Epidemiology and etiology of benign prostatic hyperplasia and bladder outlet obstruction. Indian journal of urology: IJU: journal of the Urological Society of India. 2014 Apr; 30(2):170.
19. Taneja Y, Ram P, Kumar S, Raj K, Singh CK, Dhaked SK and Jaipuria J. (2017): Comparison of Visual Prostate Symptom Score and International Prostate Symptom Score in the evaluation of men with benign prostatic hyperplasia: A prospective study from an Indian population. Prostate International., 5(4):158-61.

20. Trumbeckas D, Milonas D, Jievaltas M, Matjosaitis AJ, Kincius $M$, Grybas $A$ and Kopustinskas V. (2011): Importance of prostate volume and urinary flow rate in prediction of bladder outlet obstruction in men with symptomatic benign prostatic hyperplasia. Central European journal of urology, 64(2):75.

21. Xu D, Cui X, Qu C, Yin L, Wang C and Chen J. (2014): Urodynamic pattern distribution among aged male patients with lower urinary tract symptoms suggestive of bladder outlet obstruction. Urology, 83(3):563-9. 


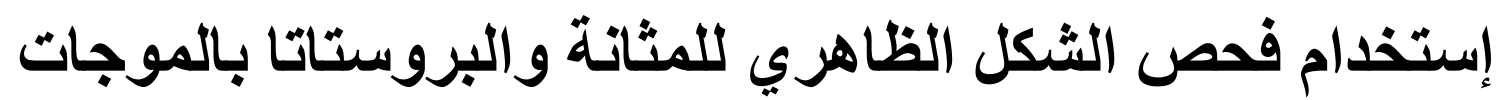
فوق الصوتية في تثخيص الانسداد البولي لادى مرضى تضخم البروستاتا الحميد

إسماعيل فتوح إسماعيل، صبري محمود خالد، أبوالفتوح عبدالمجيد أبوالفتوح، مراد محمود مراد

قسم جراحة المسالك البولية، كلية الطب، جامعة الأزهر، القاهرة، مصر

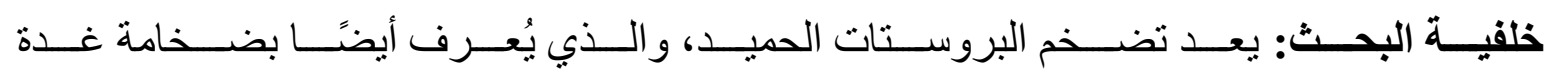

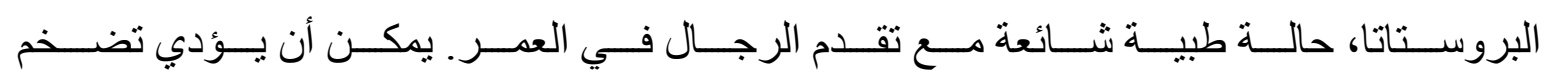

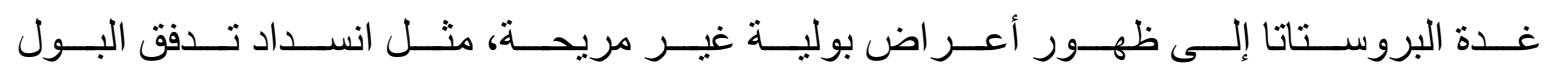

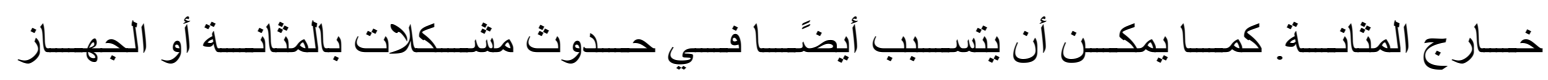

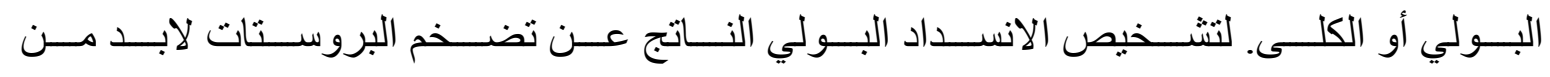

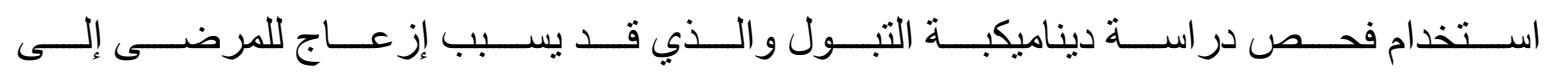
جانب كونه مكلف وغير متاح فى كل أماكن تقديم الخدمه الصحيه.

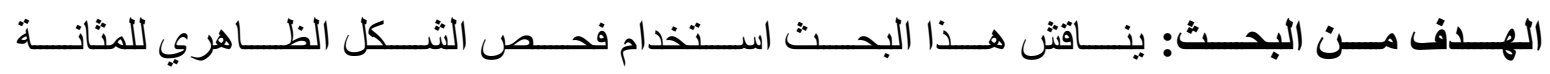

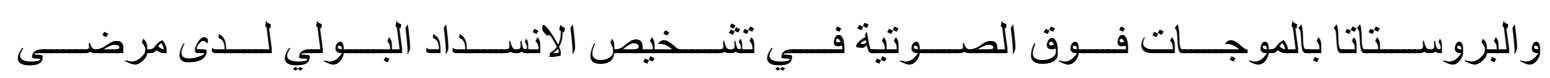
تضخم البروستانا الحميد كبديل لاستخدام فحص در اسة ديناميكبة التبول.

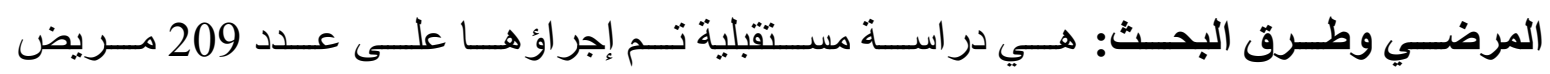

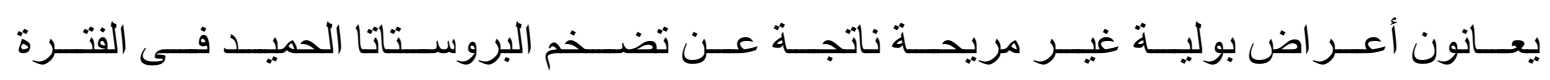

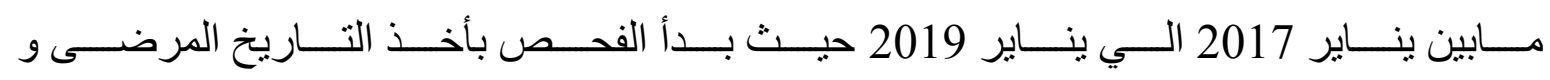

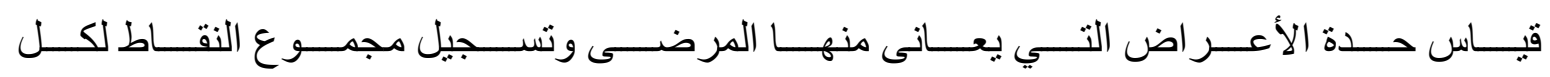

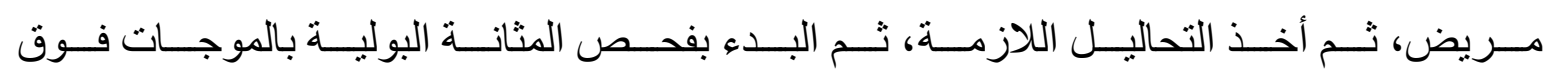

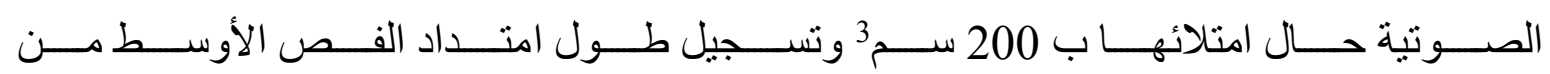

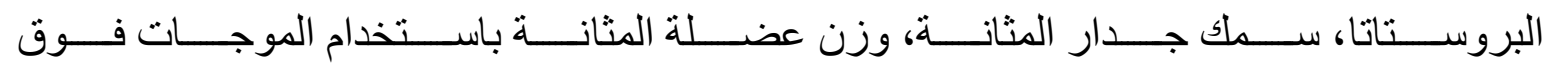

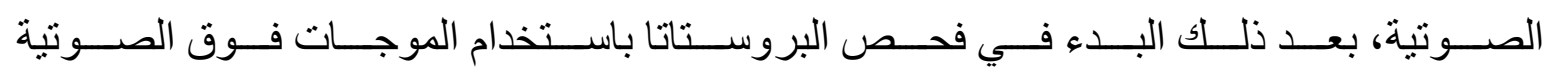

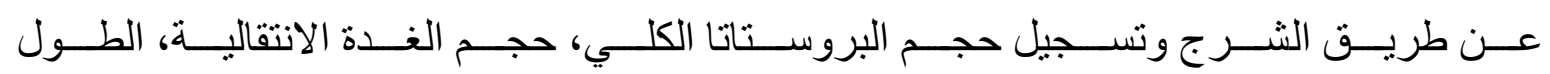

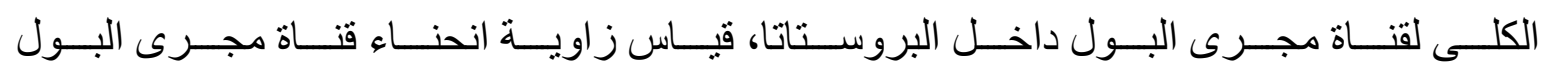




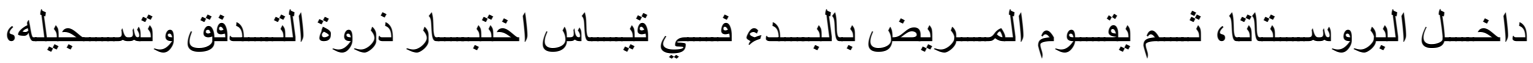

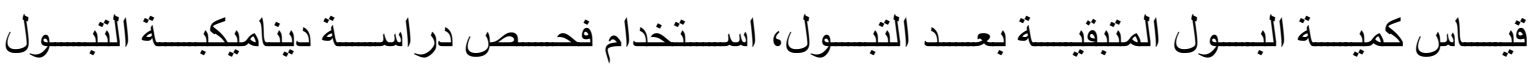

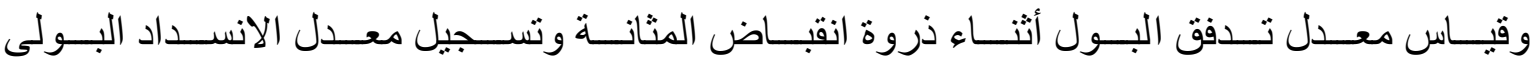

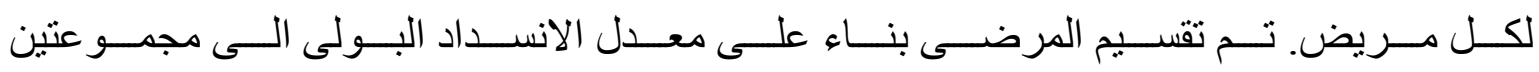

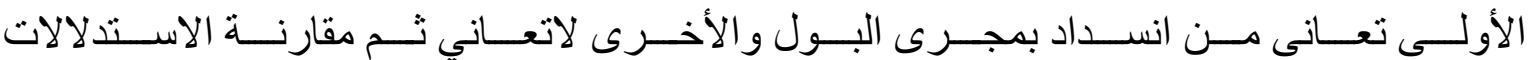
السابق تسجيلها بين المجمو عتين باستخدام الاختبار ات الاحصائية.

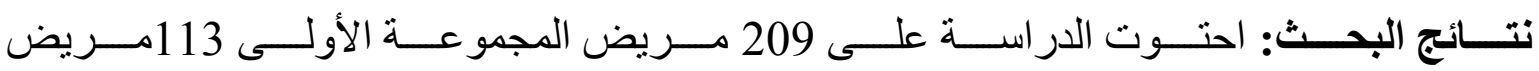

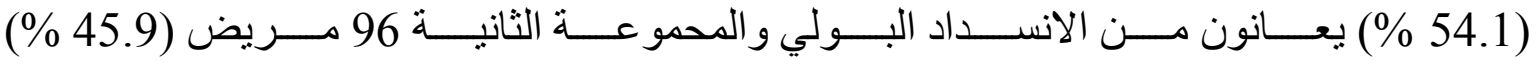
لا يعــانون منــى الانســـداد البــولي. متوســـ أعمـــار المرضــى فــى المجموعــة الأولــى 64

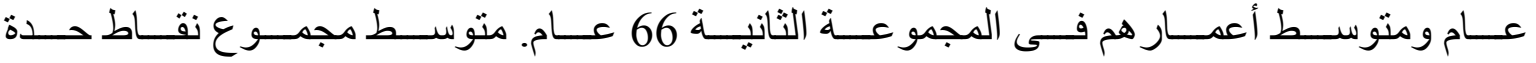

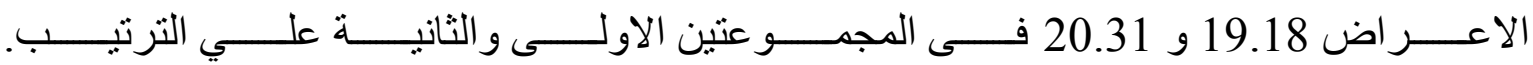

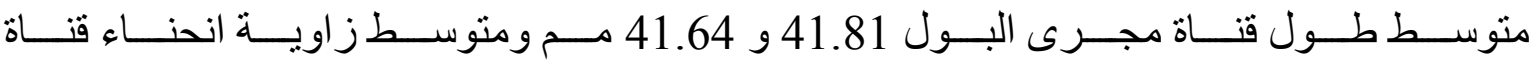

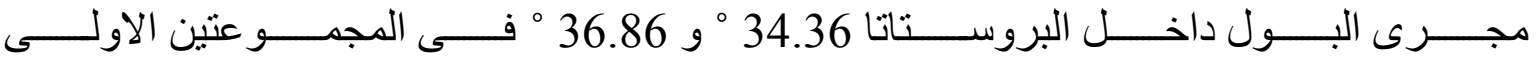

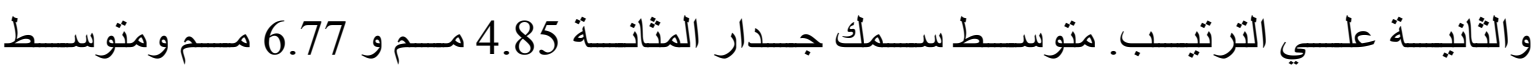

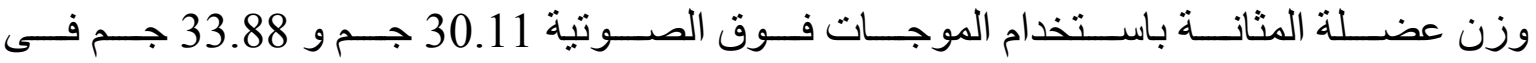

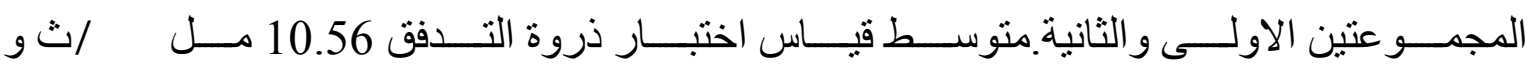

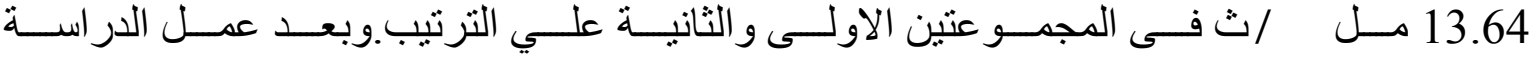

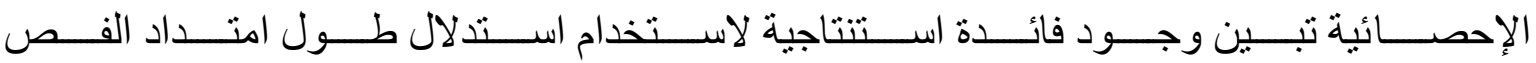

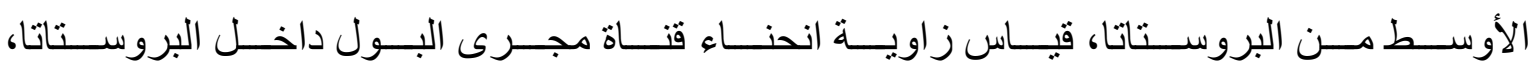
سمك جدار المثانة و اختبار ذروة التدفق للتنبؤ بانسداد مجري البول.

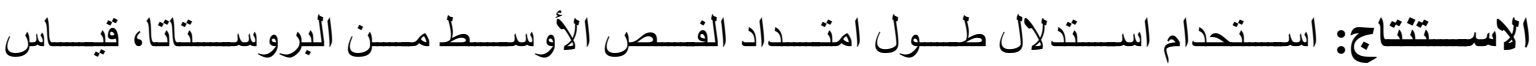

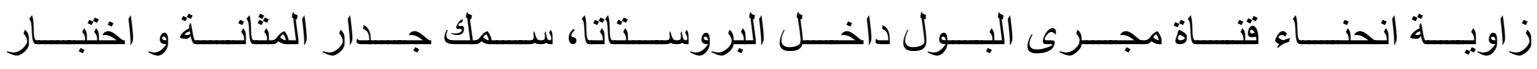

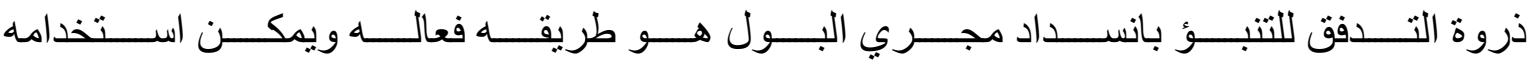
لتشخيص انسداد مجرى البول الناتج عن تضخم البروستاتا الحميد. 